\title{
Las sexualidades femeninas en la pequeña pantalla
}

\section{Female sexualities on the small screen}

Fechas | En edición: 05/06/2019 - Publicación final: 01/07/2019

\section{Sara REBOLLO-BUENO}

Universidad de Sevilla. España. sarrebbue@gmail.com

\section{Sexo y series. Las sexualidades femeninas, una revolución} televisiva

Autora: Iris BREY.

Sevilla: Héroes de papel. Crossover, 2018.

236 páginas

ISBN: 978-84-948168-9-5

\section{Resumen}

Sexo y series. Las sexualidades femeninas, una revolución televisiva es un análisis del tratamiento de la sexualidad femenina en las series de televisión estadounidenses. La obra ayuda a entender cómo se exponen las sexualidades femeninas en la pequeña pantalla y cómo esto está suponiendo una revolución, puesto que este tema ha estado rodeado de un halo de misterio y tabú en la cultura de masas.

\section{Palabras clave}

Cultura de masas; género; series; sexualidad.

\begin{abstract}
'Sex and series. Female sexualities, a television revolution' is an analysis of the treatment of female sexuality in American television series. This book helps to understand how female sexualities are exposed on the small screen and how this is implying a revolution, since this subject has been surrounded by a halo of mystery and taboo in mass culture.
\end{abstract}

\section{Keywords}

Gender; mass culture; sexuality; tv series. 
El papel de la mujer dentro de la cultura hegemónica ha sido un tema muy recurrente en los estudios de comunicación de masas. Sin embargo, parece que todavía la sexualidad de la mujer está recubierta de un halo de misterio y cierto tabú para los espectadores. Por esto, Iris Brey con Sexo y series. Las sexualidades femeninas, una revolución televisiva consigue vislumbrar a sus lectores con respuestas, proporcionando una visión sobre la revolución que suponen las series de televisión estadounidenses para el entendimiento y la visibilización de las sexualidades femeninas. La autora de esta obra hace un análisis de diferentes temáticas dentro de las sexualidades femeninas, recogidas en una introducción, cuatro capítulos sobre diferentes aspectos de la sexualidad y una conclusión, que permite al lector tener una imagen de lo que han supuesto estos productos de la cultura de masas para la representación de la mujer y el sexo.

Los medios de comunicación de masas son uno de los canales por los que la cultura se transmite a los espectadores, creando así una perspectiva del mundo que les rodea. 'Las series tienen una función educativa dentro de la sociedad. El placer femenino es un concepto que no existe en los libros escolares ni en el discurso parental' (pág. 36). Ante esta capacidad de los medios, hacer un estudio sobre temas específicos, como las series y el sexo respecto a la mujer, se convierte en imprescindible para conocer más sobre la sociedad, sus actuaciones y la imagen que se les proyecta a los receptores. Iris Brey aporta una perspectiva no solo a nivel teórico, sino con ejemplificaciones constantes que permiten al lector acudir a las series mencionadas y comprobar qué sienten y piensan ellos y su correspondencia con las palabras de la autora.

La primera toma de contacto que ofrece Brey es una introducción donde expresa su propia experiencia a la hora de enfrentarse a la realización de la obra que el lector tiene entre sus manos. Asimismo, afirma que 'esta obra estudia la forma en que la representación de la sexualidad femenina en las series desencadena una revolución. Una revolución directamente ligada a la evolución que ha sacudido el seno de la industria' (pág. 35). De esta forma, pone de relieve la importancia y la revolución que las series conllevan para la representación de la sexualidad femenina en la cultura de masas. Se trata de una aportación sobre la temática que parece haber estado invisibilizada anteriormente. Según el lector va avanzando en el texto podrá descubrir de qué revolución se trata y por qué es en sí una revolución, palabra con un gran peso semántico y que no pasa desapercibida.

Tras la introducción, la autora expone cuatro grandes bloques a través de los cuales explora el placer femenino y la representaciones de este en las series de televisión. No obstante, pone especial atención a la violencia que rodea las relaciones sexuales y a la mujer.

En el primer capítulo, 'El sexo y la palabra', Brey consigue transmitir la trascendencia de las palabras para poder definir y transmitir al espectador unos valores u otros. Se expresa en estas primeras páginas la idea de que las series de televisión han conseguido adueñarse de la sexualidad, generando un vocabulario, tanto verbal como visual, para darle una definición y un nombre a uno de los misterios actuales: la sexualidad femenina. Por esto, 'El sexo y la palabra' se divide en diferentes partes. La primera de estas es 'Clítoris, la palabra prohibida', en la que Iris Brey expone cómo aparece el término 'clítoris' en las series de televisión y explica el proceso de borrado que sufrió dicho término. A este epígrafe le sigue 'El lenguaje televisivo en la educación de los adolescentes', donde la autora afirma que algunas series que expone en dicho apartado «vehiculan» la ideas que culpabilizan el placer femenino. Una chica «de bien» no se corre' (pág. 61). Finalmente, este capítulo cierra con dos epígrafes de gran relevancia 'El consentimiento' y 'El placer de las palabras', donde se explica tanto el hecho de reconocer el consentimiento en las series de televisión como la dificultad que supone hablar de masturbación femenina en estas.

El segundo capítulo de esta obra se titula 'El placer en femenino', donde Brey expone que este concepto está asociado a otros dos términos en la mente de los receptores: el misterio y el poder. Los epígrafes que componen este capítulo son 'Los preliminares', 'La masturbación', 'El cunnilingus', 'El orgasmo' y 'El placer prohibido para madre y mujeres menopáusicas'. A través de estos apartados la autora hace un recorrido por la visión del placer que se da en las series de televisión de Estados Unidos. Este capítulo abarca desde el inicio de las relaciones sexuales, con los preliminares, hasta el orgasmo, sin olvidarse del papel que supone ser madre o una mujer menopáusica en las series de televisión, cuyos papeles prácticamente están relegados a que su placer y disfrute sexual sea casi inexistente o nulo. Brey menciona varias series donde todo esto puede ser detectado por el espectador, comparándolas con productos culturales que sí incluyen estas temáticas en sus tramas.

El capítulo que ocupa la tercera posición, 'La violencia', señala cómo la sexualidad femenina está rodeada de violencia: 'Violencia sufrida, violencia experimentada: la sexualidad femenina está impregnada de violencia. Los personajes femeninos son víctimas de esta violencia' (pág. 123). Sin embargo, en el primer apartado, 'El BDSM', se expone cómo, en ciertas ocasiones, la violencia y el placer pueden ser compatibles. Asimismo, con sus otros tres capítulos, 'La violencia racializada', 'La violación' y 'El incesto', profundiza en el papel tan relevante que tiene la violencia para escenificar la sexualidad 
femenina en las series, aportando, además, un desarrollo argumental sobre cómo se aborda el incesto desde la brutalidad y la violencia, definiéndose en la ficción como una práctica sexual con una relación estrecha con la violencia extrema. Se destacan varios casos de series de televisión que recogen dicha relación de causalidad, entre ellos, el de Juego de Tronos, donde Cersei mantiene una relación incestuosa con su hermano Jaime y, también, con su primo: 'El incesto en el caso de Cersei, tiene consecuencias devastadoras para ella, mientras que a los hombres que la han violado (Jaime o su primo) nadie los castiga' (pág. 160).

El cuarto capítulo de la obra de Iris Brey, se titula 'Las sexualidades queer'. Gracias a este, el lector se sumerge en las diferentes sexualidades que se experimentan y se exponen en las series de televisión estadounidenses. Se realiza un recorrido por sus apartados: 'La bisexualidad, una categoría en vías de extinción', 'Las sexualidades lesbianas', 'Las lesbianas butch' y 'La sexualidad de personajes transgéneros MTF (male to female)'. Cada uno, da una perspectiva más profunda de las sexualidades, dejando atrás el mito de que lo heteronormativo es lo único que se experimenta en la cultura de masas, aunque, obviamente, es lo más abundante al tratarse de 'la norma' social más extendida: 'La sexualidad de las mujeres lesbianas, bisexuales y transgéneros se han quedado al margen de la cultura dominante. Estas sexualidades, gracias a las series de televisión, han ido encontrando poco a poco su lugar en nuestras pantallas' (pág. 173).

Por último, Sexo y series. Las sexualidades femeninas, una revolución televisiva finaliza con un capítulo dedicado a las conclusiones de la autora tras todo su análisis. En dicha sección del libro, Brey pretende señalar que uno de sus objetivos es mostrar que las series de televisión estadounidenses están consiguiendo crear una gama más extensa sobre las diferentes sexualidades femeninas que se proyectan en la pequeña pantalla y que, por ende, supone una revolución en sí. Esto le permite a los espectadores conocer la variedad de sexualidades femeninas que hay y pueden encontrarse, dejando claro que los modelos tradicionales con los que se representaba a la mujer y su sexualidad han quedado totalmente obsoletos. Iris Brey expone que esto se está consiguiendo en el ámbito de las series de televisión gracias a la introducción de mujeres en puestos laborales específicos.

Cabe mencionar que, durante las conclusiones, la autora también explica otras temáticas no recogidas en los capítulos anteriores, como la sexualidad de mujeres que tienen alguna discapacidad, las cuales todavía no cuentan con la representación que merecen en las series de televisión ni en el resto de productos de la cultura de masas.

En definitiva, Sexo y series. Las sexualidades femeninas, una revolución televisiva, supone una perspectiva totalmente novedosa sobre la representación de la mujer y su sexualidad en el ámbito de las series de televisión estadounidenses. Su gran relevancia no reside solamente en su interés lúdico y cultural, sino también a nivel académico, puesto que aporta una óptica novedosa sobre la sexualidad en la cultura de masas y los estudios de género. 